Recent Advances in Communication, Electronics \& Electrical Engineering

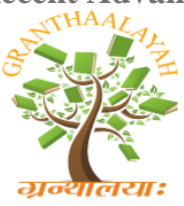

RACEEE - 17

\title{
MODELING AND SIMULATION OF WIND TURBINE COUPLED WITH A PERMANENT MAGNET SYNCHRONOUS GENERATOR UNDER GRID CONNECTED SYSTEM
}

\author{
Nagendra K ${ }^{* 1}$, Chandan Kumar ${ }^{2}$, Gowri P N ${ }^{3}$, Prathika M S ${ }^{4}$, Kavyashree D ${ }^{5}$ \\ $* 1,2,3,4,5$ Department of Electrical and Electronics Engineering, School of Engineering and \\ Technology, Jain University, Karnataka- 562112, India
}

DOI: https://doi.org/10.29121/granthaalayah.v5.i4RACEEE.2017.3319

\begin{abstract}
The objective of this paper is to model and simulate the grid connected wind mill using MATLAB/SIMULINK. Wind energy is a renewable energy and its running cost negligible as wind is freely available. The non -renewable energy are being exhausted and therefore there is a need to switch to renewable sources of energy. For utilizing wind energy, wind turbines are used and different parameters like, shape and size of the blades, wind speed, generator characteristics etc. are considered in calculating the efficiency of the turbine. This paper deals with the performance study of the output from the permanent magnet synchronous generator PMSG coupled with the wind turbine. In this case performance test is conducted with two variable speeds and the reactive power, active power, voltage and current waveforms of the inverter is plotted using SIMULINK.
\end{abstract}

Keywords: PQ Control; Voltage Source Inverter (VSI); Boost Converter; Permanent Magnet Synchronous Generator (PMSG).

Cite This Article: Nagendra K, Chandan Kumar, Gowri P N, Prathika M S, and Kavyashree D. (2017). "MODELING AND SIMULATION OF WIND TURBINE COUPLED WITH A PERMANENT MAGNET SYNCHRONOUS GENERATOR UNDER GRID CONNECTED SYSTEM." International Journal of Research - Granthaalayah, 5(4) RACEEE, 29-35. https://doi.org/10.5281/zenodo.580621.

\section{Introduction}

Day by day, the gap between electricity generation and the demand for it is rapidly increasing. This is due to extinction of fossil fuels which is one of the main sources of electricity generation. So there is a need to find an alternative way by which we can generate electricity more efficiently and the best way to generate electricity efficiently is by utilization of renewable sources of energy. There are lot many sources of energy like solar, wind, hydro, tidal, geo- 
Recent Advances in Communication, Electronics \& Electrical Engineering thermal, etc. are available in nature which can be converted into electricity. But the problem is that the complete energy which are available in nature are not able to convert into electricity energy due to the lack of technology but compared to all other sources of energy the amount of wind energy that can be converted into electricity is much higher. And the design used in harvesting wind energy is also simpler than the other forms. Since wind energy is abundantly available in nature, it is inexhaustible and sustainable energy. The economical way to generate of electrical energy is by using wind energy. The two main factors which causes wind are one is convection currents which are generated from heating and cooling of atmospheric air. The heating and cooling is caused by the solar energy absorption by the ground and the atmosphere. Second is due to the earth orbitary motion around the sun and the rotation of the earth. The wind energy has a higher potential in terms of power generation.. The conversion of wind energy to electric energy is done under different stages, extraction of wind energy using wind turbine. (Wind energy to mechanical energy) and using generators electricity is generated. Usually the wind mills are placed on land, but now a day offshore windmills are increasing. The reasons for offshore windmills are 1) population increase 2) the high wind speeds are recorded in offshore.

In wind mills both synchronous and induction generators are used for electricity generation. Cage rotor type, wound rotor type with slip control and doubly fed induction rotor type are the three types of induction generators which are used in wind mills. Among those three types, doubly fed induction rotor type gives different speed variations. So in most of the case this type of induction generator is preferred. However in this case we are using a multi-pole permanent magnet synchronous generator (PMSG) for the purpose of simulation and modeling and the modeling will be done on the grid connected system. The performance text of the generator is done using the MATLAB. The PMSG is coupled with wind turbine model and its performance is studied with changing wind speed also the output of the PMSG generator is recorded. By using the data available from the performance text the voltage and current graph of the generator and the graph which shows the relation between the wind turbine speed and the voltage produced by the generator is also plotted using MATLAB.

\section{Modelling of Wind Turbine}

Due to the torque applied to a drive train by the wind, the conversion of wind energy to mechanical energy takes place. The significance of modelling the wind turbine is to evaluate the power and torque produced in a wind turbine for a given wind speed and effect of wind speed variations on the produced torque.

$$
\begin{aligned}
& \mathrm{P}_{\mathrm{m}}=\mathrm{C}_{\mathrm{p}}(\lambda, \beta) \frac{\rho \mathrm{A}}{2} \mathrm{~V}_{\text {wind }}{ }^{3} \\
& \mathrm{C}_{\mathrm{q}}=\frac{\mathrm{C}_{\mathrm{p}}}{\lambda} \\
& \mathrm{T}=\frac{\mathrm{P}_{\mathrm{m}}}{\omega}=\frac{1}{2} \rho \prod \mathrm{R}^{3} \mathrm{C}_{\mathrm{q}}(\lambda, \beta) \mathrm{V}_{\text {wind }}{ }^{2} \\
& \lambda=\frac{\mathrm{R} * \omega}{\mathrm{V}_{\text {wind }}}
\end{aligned}
$$


Recent Advances in Communication, Electronics \& Electrical Engineering

Where,

$\mathrm{P}_{\mathrm{m}}=$ Power produced by wind turbine

$\mathrm{T}=$ Torque produced by wind turbine

$\mathrm{V}_{\min }=$ Minimum wind speed

$\mathrm{V}_{\max }=$ Maximum wind speed

$\mathrm{C}_{\mathrm{p}}=$ Performance coefficient

$\mathrm{C}_{\mathrm{q}}=$ Torque coefficient

$\mathrm{P}=$ Density of the air

$\mathrm{V}_{\text {wind }}=$ Speed of the wind

$\mathrm{A}=$ Effective area of the turbine

$\mathrm{R}=$ Turbine blade radius

$\mathrm{T}=$ Torque produced by wind turbine

$\omega=$ Angular frequency

$\beta=$ Pitch angle of the blades

$1 / 2 \rho \mathrm{A} \mathrm{V}_{\text {wind }}{ }^{3}=$ Kinetic energy produced by the wind turbine

$\lambda \quad=$ Tip speed ratio

The amount of kinetic energy captured by the wind turbine is calculated by performance coefficient $\left(\mathrm{C}_{\mathrm{p}}\right)$ and it depends on the tip speed ratio and the blade pitch angle of the wind turbine. In equation $5 . \mathrm{C}_{\mathrm{p}}$ is described as a nonlinear model.

$C_{p}(\lambda, \beta)=C_{1}\left(\frac{C_{2}}{\lambda_{i}}-C_{3} \beta+C_{4}\right) e_{\lambda_{i}}^{-C_{5}}+C_{6}$

Where,

$\mathrm{C}_{1}=0.5176, \mathrm{C}_{2}=116, \mathrm{C}_{3}=0.4, \mathrm{C}_{4}=5, \mathrm{C}_{5}=21$ and $\mathrm{C}_{6}=0.0068$

$\frac{1}{\lambda_{i}}=\frac{1}{\lambda+0.08 \beta}-\frac{0.035}{\beta^{3}+1}$ 
Recent Advances in Communication, Electronics \& Electrical Engineering

\section{Simulation of Stand Alone PV System}

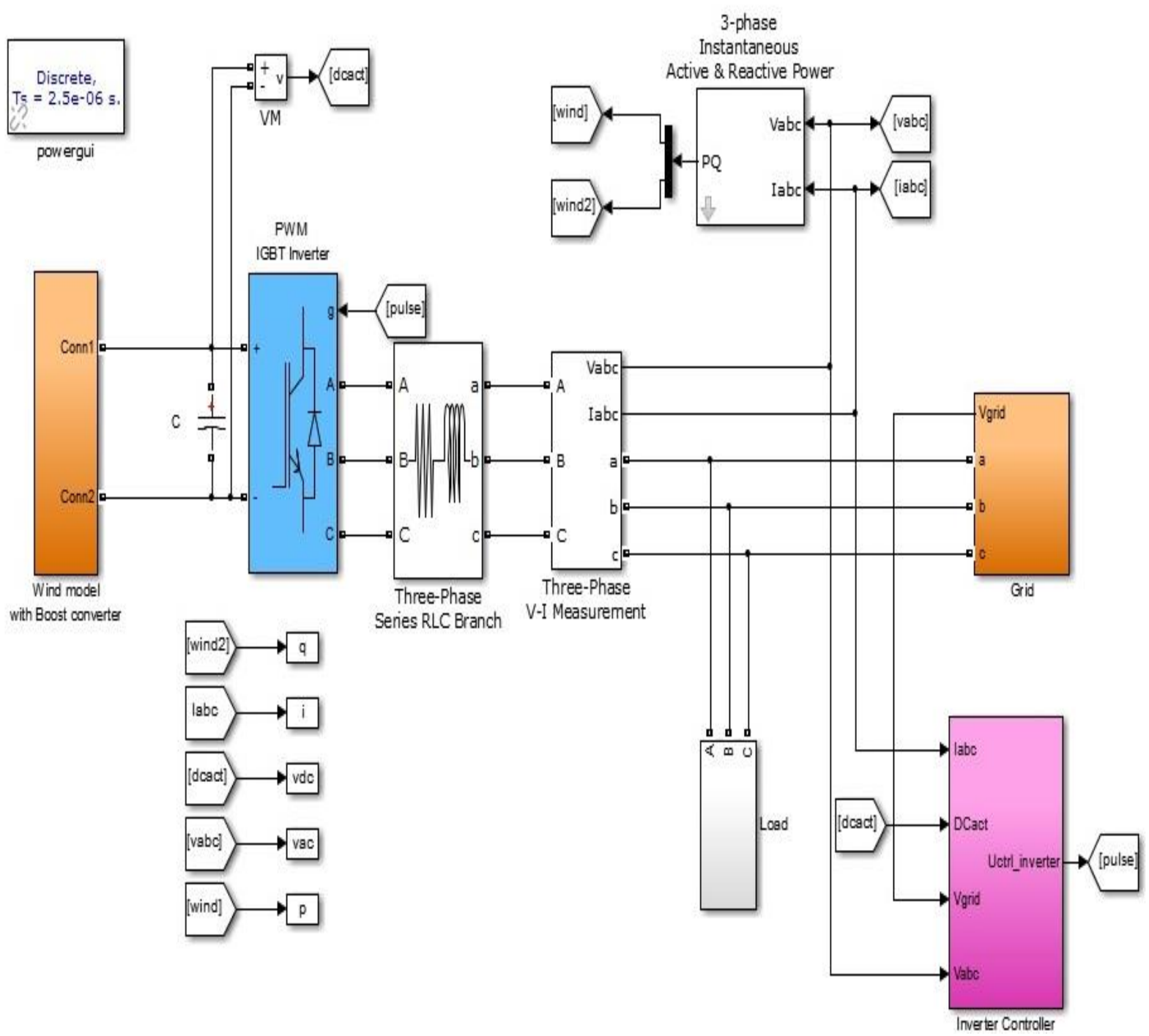

Figure 1: Simulation diagram of the PV system

Fig 1 represents the simulation diagram of the grid connected wind turbine system. In this simulation model the turbine torque from turbine model is fed to PMSG block. The output of PMSG is given to control the rectifier. The variable DC output is regulated to practical voltage using boost converter with PI tuning control load. The output of boost converter is fed to voltage source inverter through DC link. The voltage source inverter is controlled and interfaced to the grid through PQ control. The PQ control is used to control grid connected RES. Here we use Park transformation and inverse park transformation to make non linear model to linear model during PI tuning. The PI errors are given to PWM block and switching signals are generated based on the error signals to control IGBT switches of Voltage source inverter. The LC filter is used to reduce harmonics within the limits. 
[Nagendra et. al., Vol.5 (Iss.4: RACEEE), April, 2017]

ICV (Index Copernicus Value) 2015: 71.21

ISSN- 2350-0530(O), ISSN- 2394-3629(P)

IF: 4.321 (CosmosImpactFactor), 2.532 (I2OR)

InfoBase Index IBI Factor 3.86

Recent Advances in Communication, Electronics \& Electrical Engineering

4. Results

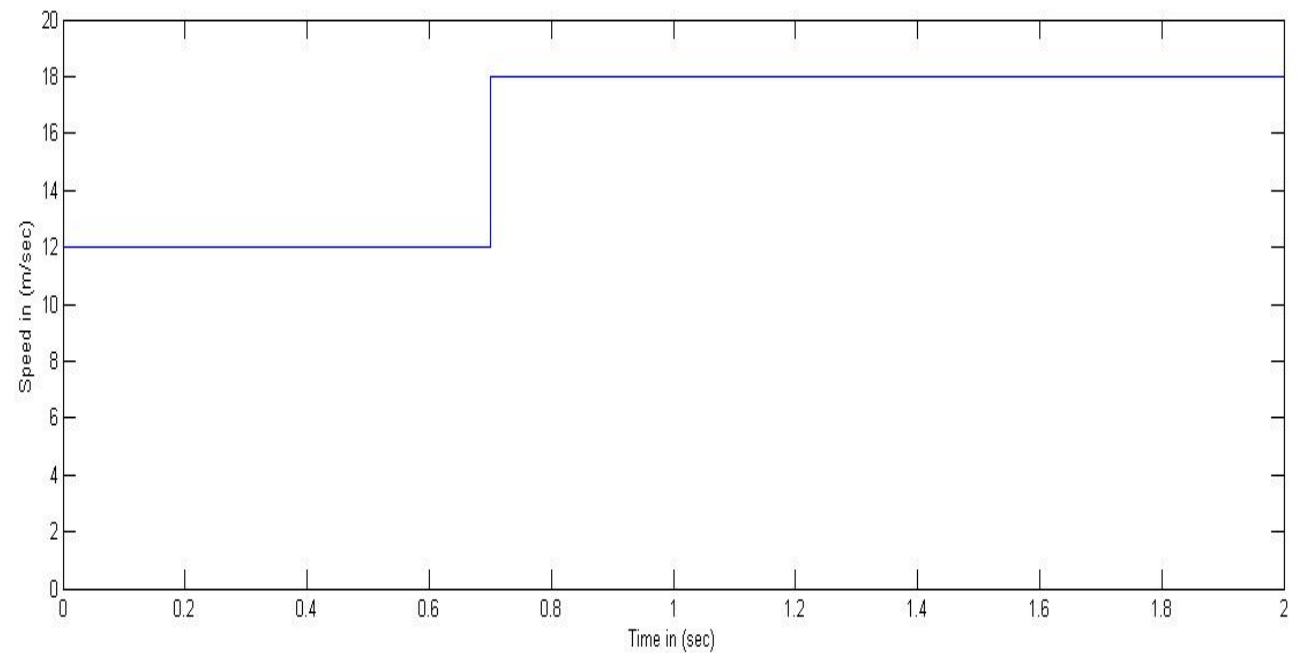

Figure 2: Wind speed variation

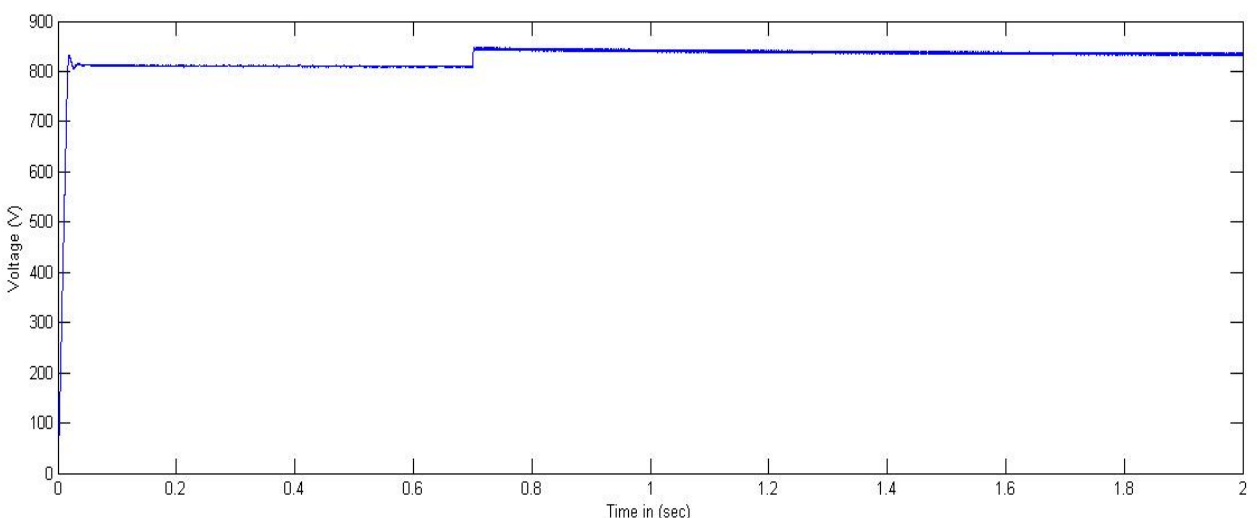

Figure 3: DC link voltage

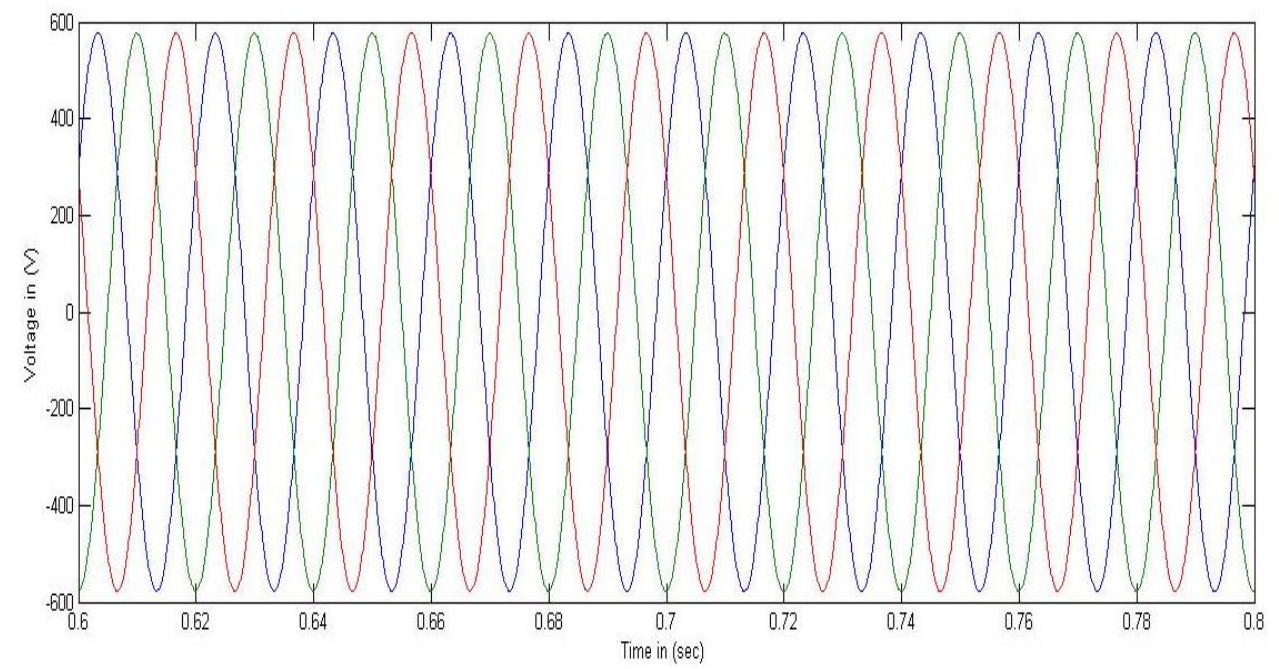

Figure 4: Inverter Voltage 
[Nagendra et. al., Vol.5 (Iss.4: RACEEE), April, 2017] ICV (Index Copernicus Value) 2015: 71.21

ISSN- 2350-0530(O), ISSN- 2394-3629(P)

IF: 4.321 (CosmosImpactFactor), 2.532 (I2OR)

InfoBase Index IBI Factor 3.86

Recent Advances in Communication, Electronics \& Electrical Engineering

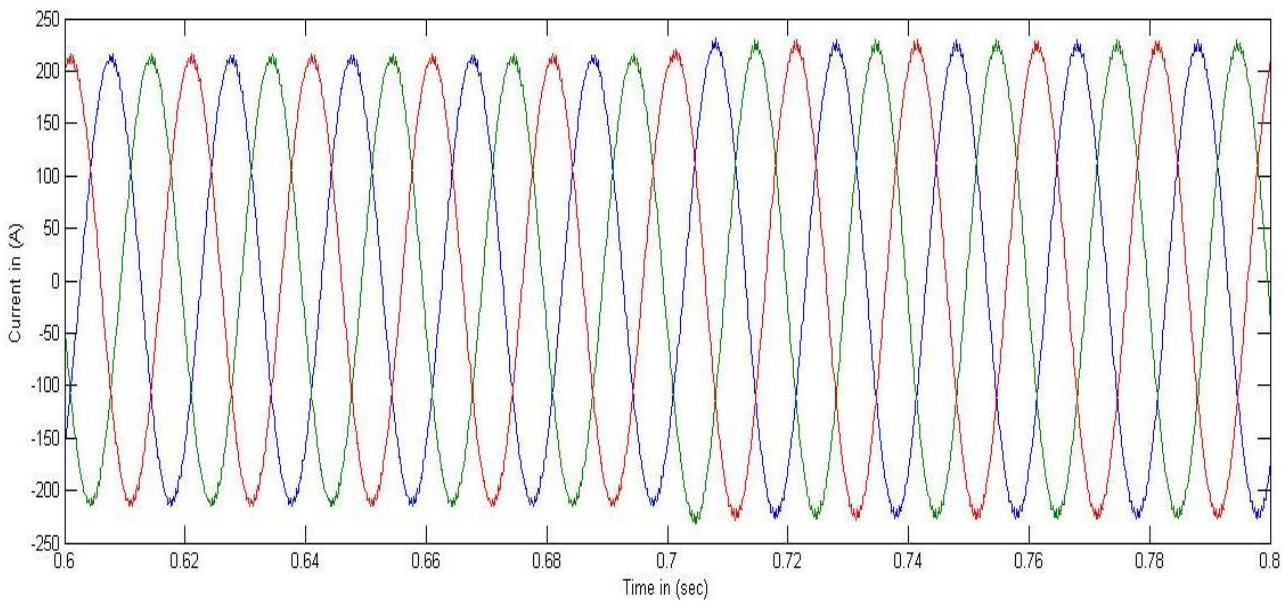

Figure 5: Inverter Current

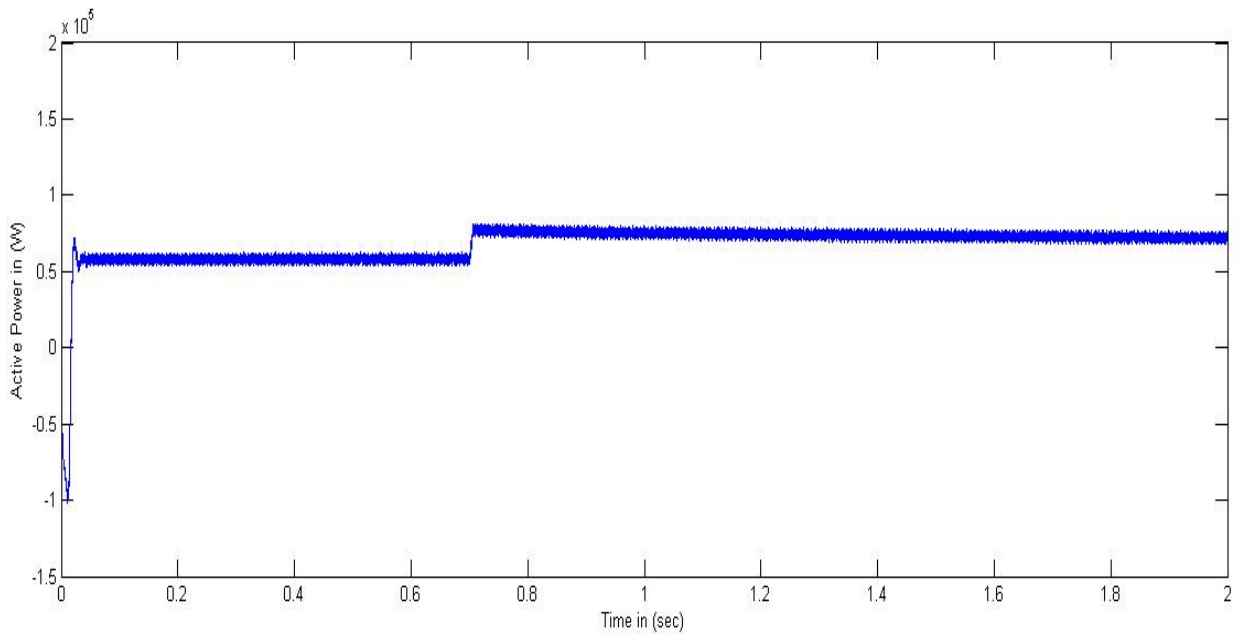

Figure 6: Active power

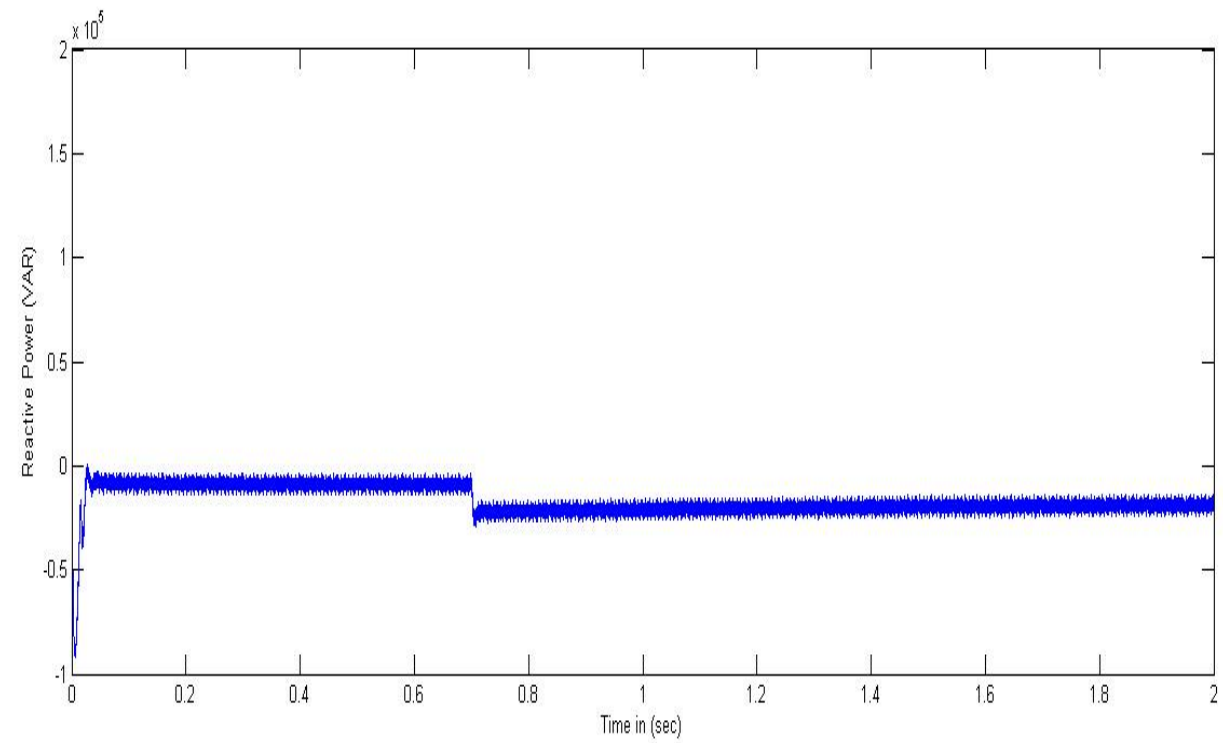

Figure 7: Reactive power 
Recent Advances in Communication, Electronics \& Electrical Engineering

\section{Conclusion}

In this paper the modeling of wind turbine is done and the torques is given to PMSG model using Simulation and it is interfaced to grid using PQ control theory. The simulated model is also studied under change in wind speed input. The dc link voltage is almost constant throughout the simulation and it's within tolerance limit of $+/-10 \%$ rated voltage. Further the PI controller tuning can be done by using adoptive fuzzy controller..

\section{References}

[1] Akshay B. Zade, Asha Gaikwad, Ku. Prachi M. Jeevane, Ganesh Lohote.: Hybrid Solar and Wind Power Generation with Grid Interconnection System for Improving Power Quality. In: International Conference on Power Electronics, Intelligent Control and Energy Systems IEEE, 2016.

[2] Sajib Chakraborty, S M Salim Reza, Wahidul Hasan.: Design and Analysis of Hybrid Solar-Wind Energy System Using CUK \& SEPIC Converters for Grid Connected Inverter Application. In: IEEE PEDS, 2015.

[3] B. M Hasaneen and Adel A. Elbaset Mohammed.: Design and Simulation of DC/DC Boost Converter. In: IEEE Power System Conference, 2008.

[4] Mubashar Yaqoob Zargar, Mairaj-ud-Din Mufti, Shameem Ahmed Lone.: Modelling and Control of Wind Solar Hybrid System Using Energy Storage System. In: International Conference on Computing, Communication and Automation, IEEE, 2016.

[5] Sunil Patel, Nayana Prajapati.: Grid Connected Solar and Wind Hybrid System. In: International Journal for Innovative Research in Science \& Technology, May 2016.

[6] Sara Ghaem Sigarchiana, Anders Malmquista, Torsten Franssona.: Modeling and control strategy of a hybrid PV/Wind/Engine/Battery system to provide electricity and drinkable water for remote application. In: ISES Solar World Congress, 2013, Energy Procedia 57 (2014) 1401 - 1410.

\footnotetext{
*Corresponding author.

E-mail address: kbnagendra@gamil.com
} 